\title{
A Protection Method of VSC-HVDC Cables Based on Generalized S-Transform
}

\author{
Weishi Man, Xiaoman Bei, Zhiyu Zhang \\ School of Electrical Engineering, Xi'an University of Technology, Xi'an, China \\ Email: beixiaoman@outlook.com
}

How to cite this paper: Man, W.S., Bei, X.M. and Zhang, Z.Y. (2021) A Protection Method of VSC-HVDC Cables Based on Generalized S-Transform. Energy and Power Engineering, 13, 1-10.

https://doi.org/10.4236/epe.2020.134B001

Received: November 12, 2020

Accepted: April 5, 2021

Published: April 8, 2021

\begin{abstract}
Generalized S-transform is a time-frequency analysis method which has higher resolution than S-transform. It can precisely extract the time-amplitude characteristics of different frequency components in the signal. In this paper, a novel protection method for VSC-HVDC (Voltage source converter based high voltage DC) based on Generalized S-transform is proposed. Firstly, extracting frequency component of fault current by Generalized S-transform and using mutation point of high frequency to determine the fault time. Secondly, using the zero-frequency component of fault current to eliminate disturbances. Finally, the polarity of sudden change currents in the two terminals is employed to discriminate the internal and external faults. Simulations in PSCAD/EMTDC and MATLAB show that the proposed method can distinguish faults accurately and effectively.
\end{abstract}

\section{Keywords}

Generalized S-Transform, VSC-HVDC, Phase-Mode Transformation, DC Cable Protection

\section{Introduction}

More and more VSC-HVDC projects are using cables as transmission lines. Due to the small damping of VSC-HVDC System, DC cable fault will cause serious over-current in a short time, which will lead to serious faults on transmission cables and the converter. In addition, VSC-HVDC system has some problems, such as fault identification, self-healing and so on [1] [2] [3]. Therefore, it is significant to study the fault characteristics of VSC-HVDC cables and realize the protection of VSC-HVDC System by analyzing the fault characteristics. The S transform was proposed in [4] and [5] by Stockwell. In [6] and [7], the feature signal is extracted by $\mathrm{S}$ transform of the fault signal. Then, the fault identifica- 
tion index is built. We use the value domain of fault index to determine the fault type. Reference [8] proposed the research of fast protection for UHVDC transmission line based on S-transform. The voltage and current components after fault are transformed by S-transform, and the polarity of voltage and current components at both ends of the line is judged by the phase difference of the whole frequency band after S-transform, so as to distinguish between internal and external faults. A protection method for HVDC transmission line based on S-transform is represented in [9]. Reference [10] and [11] use S-transform to locate fault cables through fault current. A serious drawback with S-transform in the above literature is that the time-frequency resolution of S-transform is not precise enough. In this paper, the fault current is transformed by Generalized S-transform, which has a better time-frequency resolution than S-transform. In this paper, the basic theory of Generalized S-transform and Phase-Mode transformation are introduced in Section 2. Section 3 represents the simulation model of two-terminal VSC-HVDC. The protection method is described in Section 4. Experimental results are shown in Section 5 to verify the proposed method.

\section{Basic Theory}

\subsection{Generalized S-Transform}

The S transform is a time-frequency analysis method, which derived from continuous wavelet transform and short-time Fourier transform. The S transform of a signal $x(t)$ is expressed as:

$$
\begin{aligned}
S(f, t) & =\int_{-\infty}^{\infty} \frac{|f|}{\sqrt{2 \pi}} e^{\frac{-f^{2}(\tau-t)^{2}}{2}} x(t) e^{-j 2 \pi f t} d t \\
& =\int_{-\infty}^{\infty} \omega(f, \tau-t) x(t) e^{-j 2 \pi f t} d t
\end{aligned}
$$

where: $\omega(f, \tau-t)=\frac{|f|}{\sqrt{2 \pi}} e^{\frac{-f^{2}(\tau-t)^{2}}{2}} \omega(f, \tau-t)$ is Gaussian window function with a time-shift factor $\tau$ and a frequency $f$. The $S$ transform of a discrete signal $x[m T]$ is expressed as:

$$
\begin{gathered}
S\left[\frac{n}{N T}, m T\right]=\sum_{k=0}^{N-1} X\left[\frac{k+n}{N T}\right] e^{\frac{-2 \pi^{2} k^{2}}{n^{2}}} e^{j 2 \pi \frac{k m}{N}} . \\
S[0, m T]=\frac{1}{N} \sum_{m=0}^{N-1} x[m T] .
\end{gathered}
$$

where $m=0,1,2, \ldots, N-1, N$ is the number of sampling points, and $T$ is the sampling time interval. Based on the S transform, the Generalized S-transform can be obtained and described as follow:

$$
\begin{aligned}
S(f, \tau) & =\int_{-\infty}^{\infty} \frac{\left|f^{\alpha}\right|}{|\beta| \sqrt{2 \pi}} e^{\frac{-f^{2 \alpha}(\tau-t)^{2}}{2 \beta^{2}}} x(t) e^{-j 2 \pi f t} d t \\
& =\int_{-\infty}^{\infty} \omega(f, \tau-t) x(t) e^{-j 2 \pi f t} d t
\end{aligned}
$$


where: $\omega(f, \tau-t)=\frac{\left|f^{\alpha}\right|}{|\beta| \sqrt{2 \pi}} e^{\frac{-f^{2 \alpha}(\tau-t)^{2}}{2 \beta^{2}}}$. In Equation (4), $\alpha$ and $\beta$ are regulator, positive numbers. By adjusting parameters of $\alpha$ or $\beta$, superior time-frequency characteristic of the signal is obtained.

\subsection{Phase-Mode Transformation}

The cross section of bipolar cable is shown in Figure 1. From inside to outside, there are three layers: conductor layer, sheath layer and armor layer. The voltage and current parameters in the bipolar cable are coupled with each other. It is obliged to decouple the parameters.

Reference [9] and [10], the decoupling method for the bipolar DC line was represented, which is described as follows: The sketch map of DC cable is shown in Figure 2. The output terminal of rectifier and inverter station are marked as 1

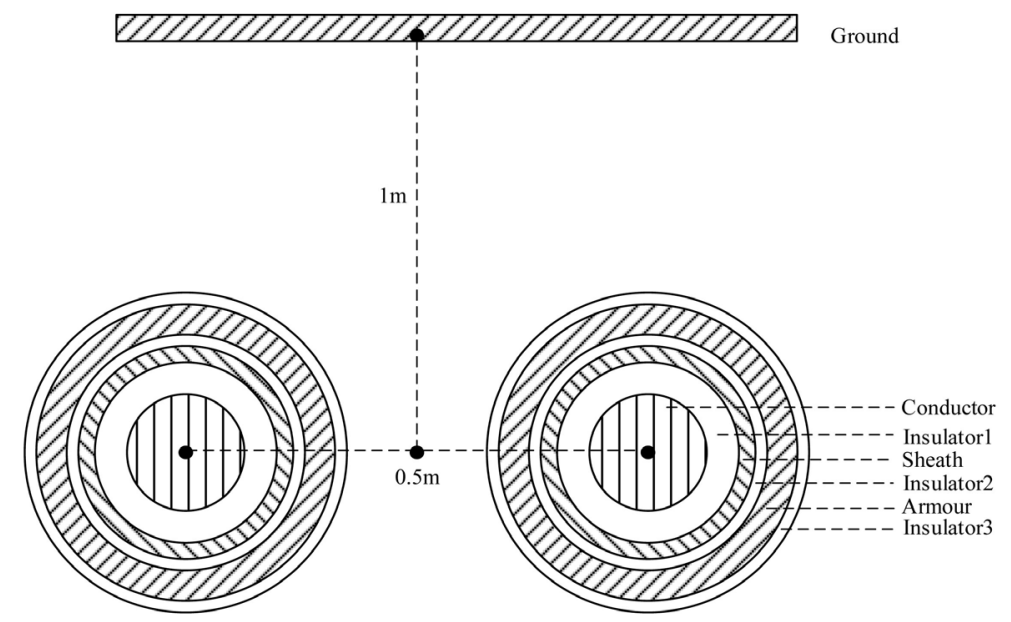

Figure 1. The cross section of biploar cable.

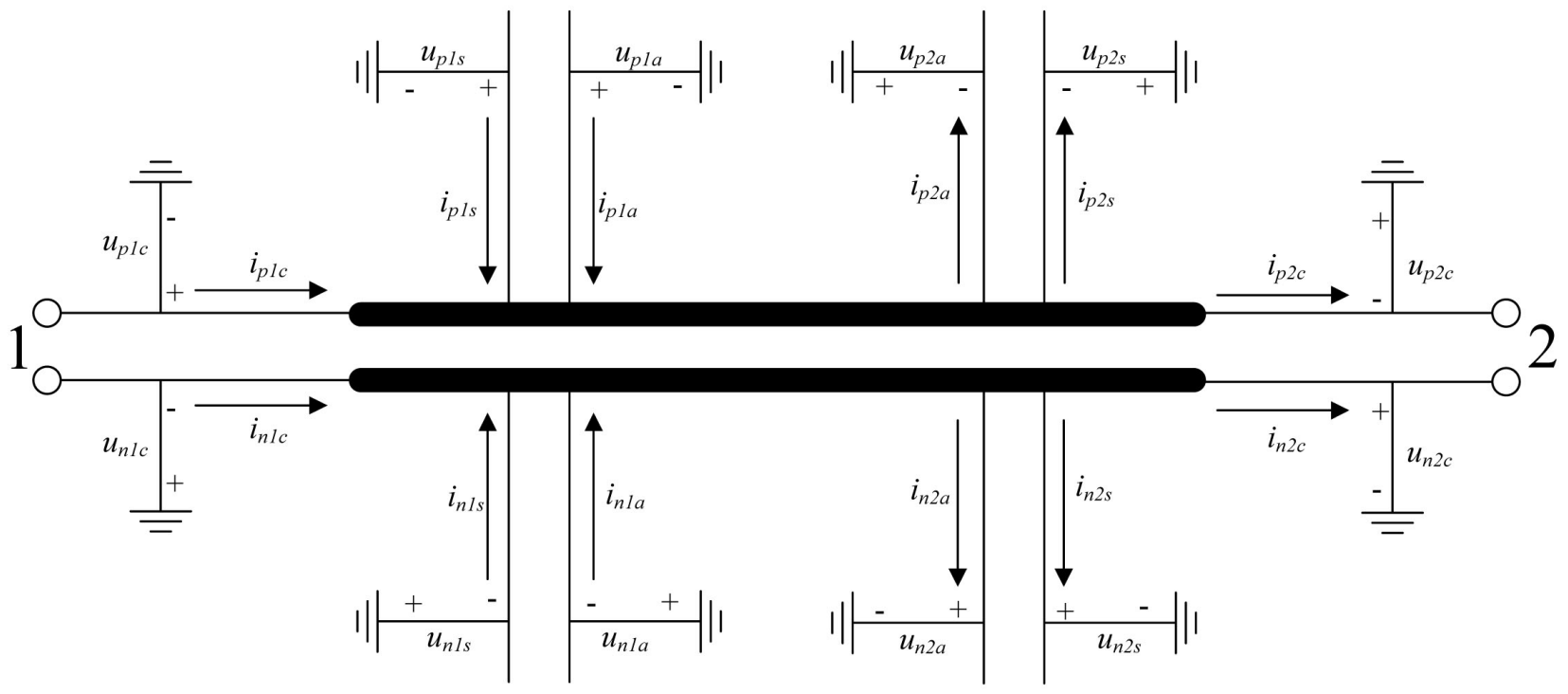

Figure 2. The sktech map of DC cable. 
and 2, respectively. Taking terminal 1 as an example, $u_{p 1 \mathcal{c}}, u_{p 1 s}$ and $u_{p 1 a}$ represents the DC voltage of conductor layer, sheath layer and armor layer of the positive cable at terminal 1 respectively. $u_{n 1 c}, u_{n 1 s}, u_{n 1 a}$ are the DC voltage of conductor layer, sheath layer and armor layer of the negative cable at terminal 1 respectively. The same applies to terminal 2.

Define $R, L, G$ and $C$ as the matrices of the resistance, inductance, conductance and capacitance per meter of the DC cable respectively, and the wave equations with mutual inductance can be represented as follows:

$$
\left\{\begin{array}{l}
\frac{\partial U_{1}}{\partial x}=-R I_{1}-L \frac{\partial I_{1}}{\partial t} \\
\frac{\partial I_{1}}{\partial x}=-G U_{1}-C \frac{\partial U_{1}}{\partial t}
\end{array}\right.
$$

$U_{1}=\left[u_{p 1 c}, u_{n 1 c}, u_{p 1 s}, u_{n 1 s}, u_{p 1 a}, u_{n 1 a}\right], I_{1}=\left[i_{p 1 c}, i_{n 1 c}, i_{p 1 s}, i_{n 1 s}, i_{p 1 a}, i_{n 1 a}\right]$. The key to realizing the decoupling is to transform $R, L, G$ and $C$ to diagonal matrices. According to this principle, the voltage phase mode transform matrix can be derived and represented as follows:

$$
\boldsymbol{P}=\boldsymbol{k} \otimes\left[\begin{array}{ccc}
\boldsymbol{I} & \boldsymbol{I} & \boldsymbol{I} \\
\boldsymbol{I} & \boldsymbol{I} & 0 \\
\boldsymbol{I} & 0 & 0
\end{array}\right]
$$

where $\mathbf{0}$ and $I$ are the 2-dimensional zero matrix and unit matrix respectively, while $\boldsymbol{k}$ is the decoupling transform matrix expressed as

$$
k=\left[\begin{array}{cc}
1 & 1 \\
1 & -1
\end{array}\right]
$$

Introduce $Q=P^{-T}$ as the current phase mode transform matrix, and Equation (3) can be transformed to

$$
\left\{\begin{array}{l}
\frac{\partial U_{1 m}}{\partial x}=-P^{-1} R Q I_{1 m}-P^{-1} L Q \frac{\partial I_{1 m}}{\partial t} \\
\frac{\partial I_{1 m}}{\partial x}=-Q^{-1} G P U_{1 m}-Q^{-1} C P \frac{\partial U_{1 m}}{\partial t}
\end{array}\right.
$$

where $I_{1 m}$ is expressed as:

$$
I_{1 m}=Q^{-1} I_{1}=\left[\begin{array}{c}
i_{p 1 c}+i_{n 1 c}+i_{p 1 s}+i_{n 1 s}+i_{p 1 a}+i_{n 1 a} \\
i_{p 1 c}-i_{n 1 c}+i_{p 1 s}-i_{n 1 s}+i_{p 1 a}-i_{n 1 a} \\
i_{p 1 c}+i_{n 1 c}+i_{p 1 s}+i_{n 1 s} \\
i_{p 1 c}-i_{n 1 c}+i_{p 1 s}-i_{n 1 s} \\
i_{p 1 c}+i_{n 1 c} \\
i_{p 1 c}-i_{n 1 c}
\end{array}\right]
$$

According to [9] and the reference direction of currents in Figure 2, the 6-th mode current is employed because its attenuation constant is lowest and the propagation velocity is close to traveling wave.

\section{Simulation Model}

Taking a two-terminal VSC-HVDC as an example, we build its system simula- 
tion model and some typical faults are carried out in PSCAD/EMTDC. The fault model is shown in Figure 3. The length between rectifier station and inverter station is $200(\mathrm{~km}), p_{1}, p_{2}, n_{1}, n_{2}$ are relay protection devices. Fault $\mathrm{F}_{1}$ is at the middle point of the positive cable. $F_{2}$ is the bipolar short-circuit fault. $F_{3}$ and $F_{4}$ are fault in the AC system, respectively. In this paper, $F_{1}$ and $F_{2}$ are internal faults, $\mathrm{F}_{3}$ and $\mathrm{F}_{4}$ are external faults.

The parameters of rectifier station and inverter station are shown in Table 1. The DC voltage in this paper is $350(\mathrm{kV})$.

\section{Protection Method}

The 6-th mode current is employed to establish criteria. The Generalized S-transform result matrix of 6-th mode current is marked as $G S_{6}$. When a fault occurs, there are abundant frequency components in the DC cable. The summation of the magnitude of high frequency $(5 \mathrm{kHz}-10 \mathrm{kHz})$ at the time $\mathrm{kT}$ can be calculated as:

$$
S_{u m}=\sum_{n_{1} \leq n \leq n_{2}}\left|G S_{6}[k+1, n+1]\right|
$$

where $n_{1} f_{0}=5 \mathrm{kHz}, n_{2} f_{0}=10 \mathrm{kHz}$. The criteria that the first sudden change time of $S_{u m}$ is the time of fault based on numerous experiments. When the VSC-HVDC operates normally, $S_{u m}$ is 0 . So the criteria of when the fault occurs can be built as follows: when $S_{u m}>S_{u m h}$, it indicates that there is a fault. $S_{u m h}$ is the threshold which is obtained in this case: the fault resistance is set to $500(\Omega)$ and during the remote fault. In this paper, $S_{u m h}$ is 0.5 . The disturbance caused by noise can also cause high frequency in the cable. To estimate the disturbance, the zero frequency of the $G S_{6}$ is employed to establish criteria, which can be obtained as follows:

$$
G S_{0}=\left|G S_{6}[k+1,1]\right|
$$

The $\Delta G S_{0}$ is the difference of 6-th mode result after Generalized S-transform when VSC-HVDC operates normally and when there is a fault or disturbance.

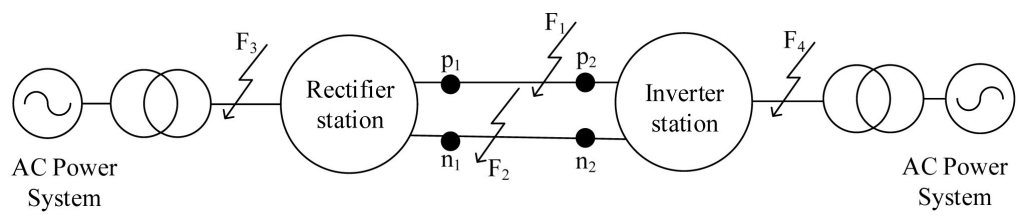

Figure 3. The fault model of VSC_HVDC.

Table 1. Parameters of VSC-HVDC.

\begin{tabular}{ccc}
\hline Station & Rectifier station & Inverter station \\
\hline Parameter & 420 & 420 \\
Rated frequency $(\mathrm{Hz})$ & 60 & 50 \\
Rated capacity (MVA) & 100 & 100 \\
\hline
\end{tabular}


Based on mounts of experiments, the criteria can be built as following: when $\left|\Delta G S_{0}\right|>h$, it indicates there is a fault, otherwise, it is disturbance. Where $h$ is threshold which should be smaller than $\left|\Delta G S_{0}^{\prime}\right| \cdot\left|\Delta G S_{0}^{\prime}\right|$ is the difference of 6-th mode current after Generalized S-transform when VSC-HVDC operates normally and when there is a remote fault with the largest resistance. In this paper, $\mathrm{k}$ is 0.8 .

It is necessary to identify the external fault from internal fault because the external fault can also cause the sudden change of sum. Take the monopole to earth fault as an example. The simplified diagram of the system after fault $F_{1}$ is shown in Figure 4. $R_{f}$ is the fault resistance and $\Delta u_{f}$ is the additional voltage source at the fault point. The voltage between the fault point and the ground is $\Delta u . Z_{p 12}$ is the equivalent impedance of cable ${ }_{12} . Z_{s 1}$ and $Z_{s 2}$ are the equivalent impedance of AC sides, respectively. Measured by the protection devices $p_{1}$ and $p_{2}$, the fault current component is named as $\Delta i_{p 1}$ and $\Delta i_{p 2}$. The reference directions of the DC currents are represented by the arrows displayed in the figure. Seen from Figure 4, the relation of $\Delta u, \Delta i_{p 1}, \Delta i_{p 2}$ can be expressed in Equation (12). From Equation (12), the polarities $\Delta i_{p 1}$ and $\Delta i_{p 2}$ are opposite.

$$
\left\{\begin{array}{c}
\Delta u=-\Delta i_{p 1} \times\left(\frac{Z_{p 12}}{2}+Z_{s 1}\right) \\
\Delta u=\Delta i_{p 2} \times\left(\frac{Z_{p 12}}{2}+Z_{s 2}\right)
\end{array}\right.
$$

The simplified diagram of the system after an external fault $\mathrm{F}_{3}$ at the rectifier side is shown in Figure 5. $Z_{s 1 f}$ is the equivalent impedance from the fault point to DC-link capacitor. The relation of $\Delta u, \Delta i_{p 1}, \Delta i_{p 2}$ can be expressed in Equation (13). Obviously, $\Delta i_{p 1}$ and $\Delta i_{p 2}$ have the same polarity.

$$
\left\{\begin{array}{l}
\Delta u=\Delta i_{p 1} \times\left(Z_{s 1 f}+Z_{p 12}+Z_{s 2}\right) \\
\Delta u=\Delta i_{p 2} \times\left(Z_{s 1 f}+Z_{p 12}+Z_{s 2}\right)
\end{array}\right.
$$

The flowchart of the protection method is expressed as follows: (Figure 6)

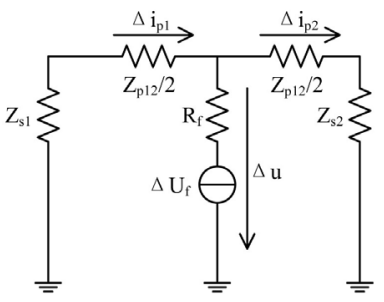

Figure 4. The simplified diagram after fault $\mathrm{F}_{1}$.

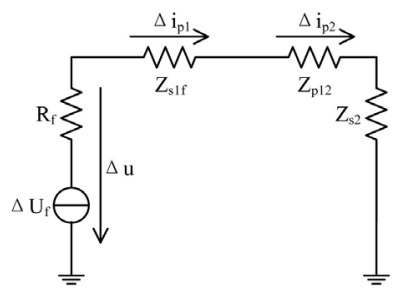

Figure 5. The simplified diagram after fault $\mathrm{F}_{3}$. 


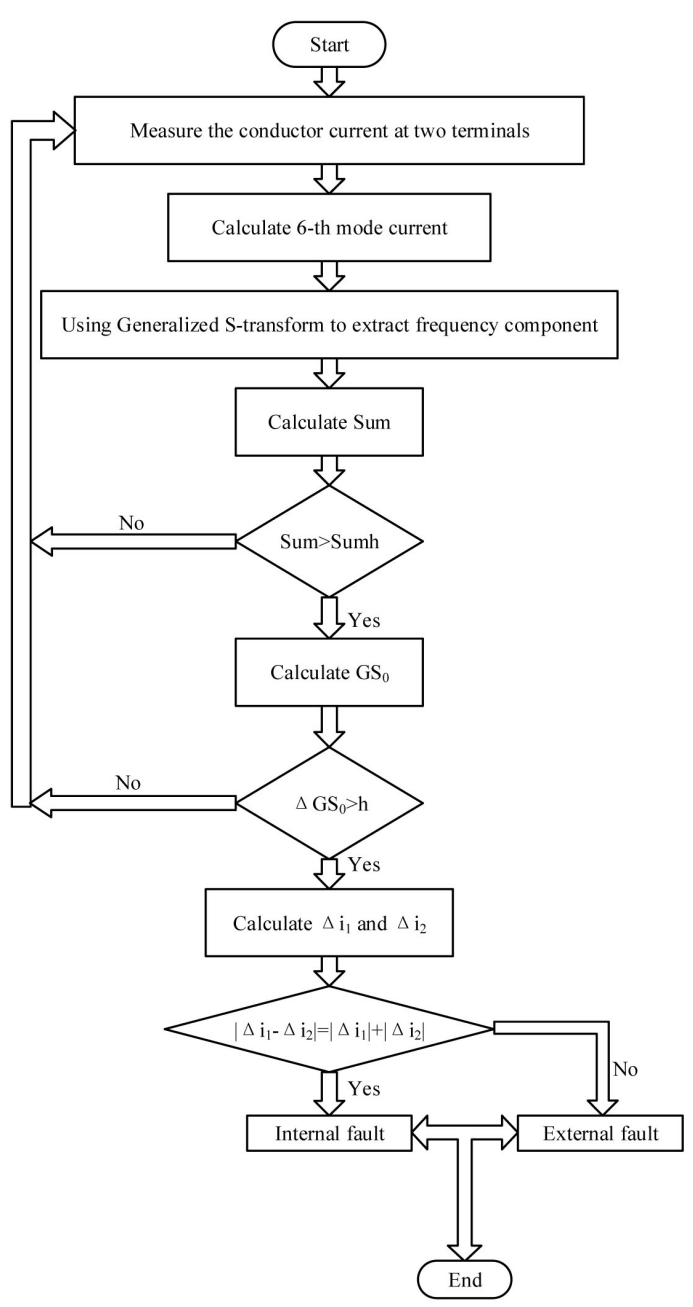

Figure 6. The flowchart of the protection method.

\section{Experiment Results}

\subsection{Internal Faults}

Internal faults are composed of monopole to earth fault and bipolar short-circuit fault. Numerous internal faults are simulated to verify the reliability of the proposed protection method, which are shown in Table 2 . This section takes the simulation results of monopole to earth fault with the fault resistance of $100(\Omega)$ at $\mathrm{F}_{1}$ as an example, which is shown in Figure 7. As shown in (a), (b), $\operatorname{IP}_{1}, \mathrm{IN}_{1}$, $\mathrm{IP}_{2}, \mathrm{IN}_{2}$ are the currents after fault measured at $p_{1}, n_{1}, p_{2}, n_{2}$, respectively. The 6-th mode current $I_{1}$ and $I_{2}$ are calculated from them. $S_{u m 1}$ and $S_{u m 2}$ are shown in (c). at $0.5 \mathrm{~s}, S_{u m 1}$ and $S_{u m 2}$ are both reach the sudden change point and the peak values are larger than $S_{u m h}$. $\Delta G S_{01}$ and $\Delta G S_{02}$ are both larger than $h$, which are shown in (d). As shown in (e), the polarities of $\Delta i_{1}$ and $\Delta i_{2}$ are opposite, which indicates that there is an internal fault in the DC cable.

\subsection{External Faults}

The simulation results of external faults are shown in Table 3 . 


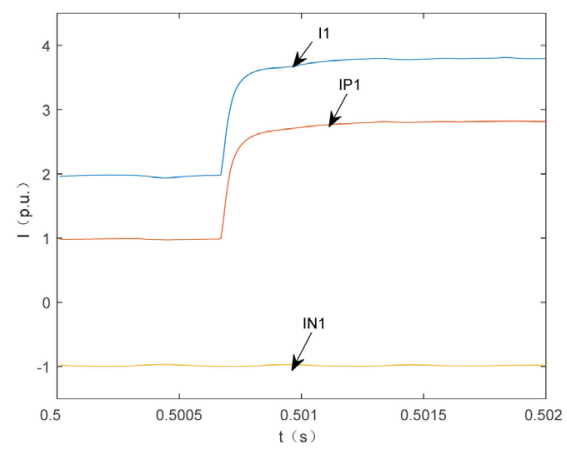

(a)

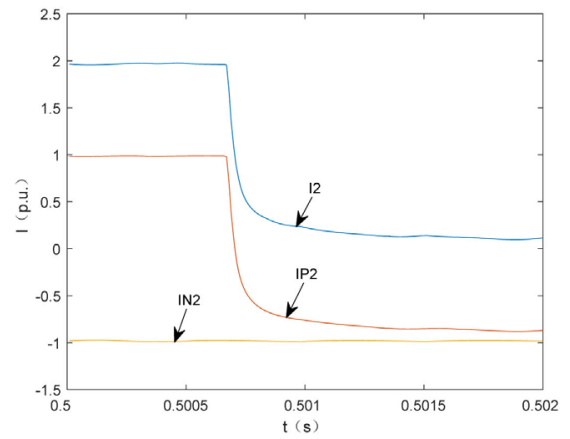

(b)

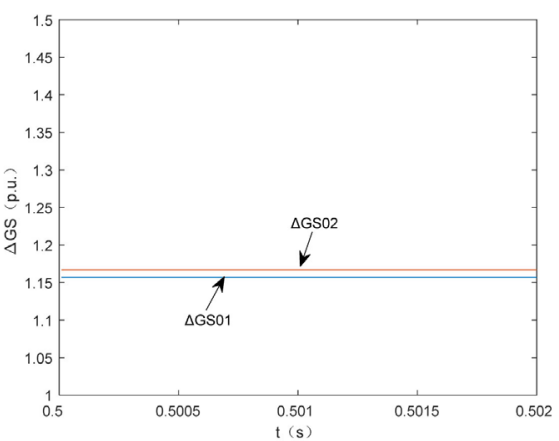

(d)

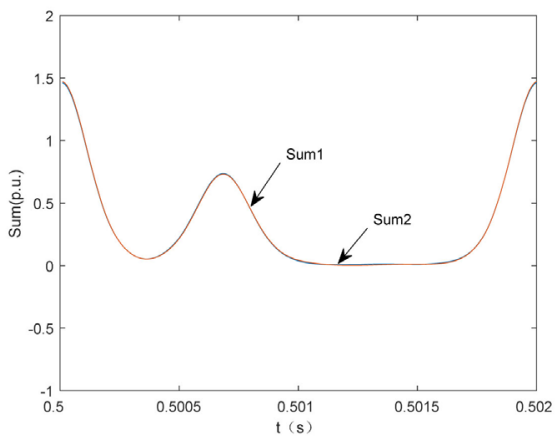

(c)

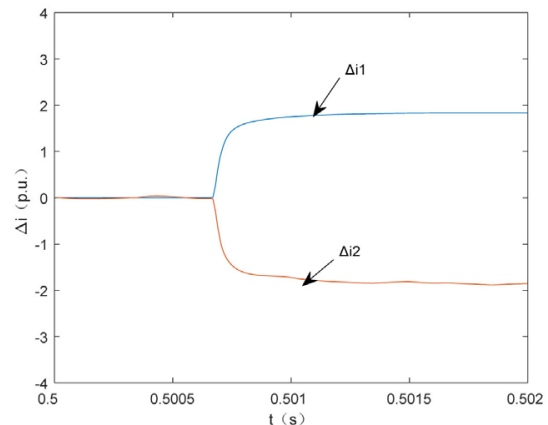

(e)

Figure 7. The simulation results for fault at $F_{1}$.

Table 2. Simulation results for internal faults.

\begin{tabular}{|c|c|c|c|c|}
\hline \multicolumn{5}{|c|}{ Simulation results for internal faults } \\
\hline Fault location & $\mathrm{F} 1$ & $\mathrm{~F} 1$ & $\mathrm{~F} 1$ & $\mathrm{~F} 2$ \\
\hline Resistance $(\Omega)$ & 0 & 200 & 500 & 0 \\
\hline$S_{u m 1}$ (p.u.) & 20.6 & 2.4 & 0.53 & 21.3 \\
\hline$S_{u m 2}$ (p.u.) & 3.3 & 0.61 & 0.12 & 23.7 \\
\hline$\Delta G S_{01}$ (p.u.) & 59.4 & 4.3 & 2.4 & 60.2 \\
\hline$\Delta G S_{02}$ (p.u.) & 1.2 & 1.7 & 1.8 & 59.3 \\
\hline$\Delta i_{1}$ (p.u.) & 300.1 & 30.2 & 7.6 & 280.3 \\
\hline$\Delta i_{2}$ (p.u.) & -80.2 & -10.2 & -2.1 & -291.5 \\
\hline
\end{tabular}


Table 3. Simulation results for external faults.

\begin{tabular}{ccccccc}
\hline \multicolumn{7}{c}{ Simulation results for external faults } \\
\hline $\begin{array}{c}\text { Fault } \\
\text { location }\end{array}$ & F3 & F3 & F3 & F4 & F4 & F4 \\
\hline Fault type & $\begin{array}{c}\text { Single-phase } \\
\text { fault }\end{array}$ & $\begin{array}{c}\text { Two-phase } \\
\text { fault }\end{array}$ & $\begin{array}{c}\text { Three-phase } \\
\text { fault }\end{array}$ & $\begin{array}{c}\text { Single-phase } \\
\text { fault }\end{array}$ & $\begin{array}{c}\text { Two-phase } \\
\text { fault }\end{array}$ & $\begin{array}{c}\text { Three-phase } \\
\text { fault }\end{array}$ \\
\hline$S_{\text {um1 }}$ (p.u.) & 13.2 & 21.3 & 23.8 & 6.3 & 7.8 & 7.9 \\
$S_{u m 2}$ (p.u.) & 5.1 & 7.6 & 7.8 & 15.7 & 23.2 & 24.1 \\
$\Delta G S_{01}$ (p.u.) & 13.7 & 15.1 & 15.3 & 6.9 & 7.2 & 7.3 \\
$\Delta G S_{02}$ (p.u.) & 2.8 & 3.4 & 3.7 & 18.2 & 19.3 & 19.4 \\
$\Delta i_{1}$ (p.u.) & -250.7 & -300.6 & -301.9 & 130.3 & 160.3 & 148.2 \\
$\Delta i_{2}$ (p.u.) & -140.4 & -160.5 & -150.3 & 250.7 & 300.8 & 320.7 \\
\hline
\end{tabular}

\section{Conclusion}

This paper proposed a novel protection method for VSC-HVDC based on Generalized S-transform. Firstly, using Generalized S-transform to extract frequency component of fault current and employing mutation point of high frequency to determine the fault time. Secondly, eliminating disturbances using the zero-frequency component of fault current. Finally, the polarity of sudden change currents in the two terminals is employed to discriminate the internal and external faults. Simulations in PSCAD/EMTDC and MATLAB show the accuracy and effectiveness of the proposed method.

\section{Conflicts of Interest}

The authors declare no conflicts of interest regarding the publication of this paper.

\section{References}

[1] Yeap, Y.M., Geddada, N. and Ukil, A. (2017) Analysis and Validation of Wavelet Transform Based DC Fault Detection in HVDC System. Applied Soft Computing, 61, 17-29. https://doi.org/10.1016/j.asoc.2017.07.039

[2] Jamali, S. and Mirhosseini, S.S. (2019) Protection of Transmission Lines in Multi-Terminal HVDC Grids Using Travelling Waves Morphological Gradient. Electrical Power and Energy Systems, 108, 125-134. https://doi.org/10.1016/j.ijepes.2019.01.012

[3] Liu, J., Tai, N.L. and Fan, C.J. (2017) Ransient-Voltage-Based Protection Scheme for DC Line Faults in the Multiterminal VSC-HVDC System. IEEE Transactions on Power Delivery, 32, 1483-1494. https://doi.org/10.1109/TPWRD.2016.2608986

[4] Stockwell, R.G., Mansinha, L. and Lowe, R.P. (1996) Localization of the Complex Spectrum: The S Transform. IEEE Transactions on Signal Processing, 44, 998-1001. https://doi.org/10.1109/78.492555

[5] Dai, Z.H., Liu, N.N., Zhang, C., Pan, X.Y. and Wang, J.Y. (2019) A Pilot Protection for HVDC Transmission Lines Based on Transient Energy Ratio of DC Filter Link. IEEE Transactions on Power Delivery, 2950350. 
[6] Zheng, J.C., Wen, M.H., Qin, Y., Wang, X.Z. and Bai, Y. (2020) A Novel Pilot Directional Backup Protection Scheme Based on Transient Currents for HVDC Lines. International Journal of Electrical Power and Energy Systems, 115, Article ID: 105424. https://doi.org/10.1016/j.ijepes.2019.105424

[7] Leterme, W. and Van Hertem, D. (2018) Cable Protection in HVDC Grids Employing Distributed Sensors and Proactive HVDC Breakers. IEEE Transactions on Power Delivery, 33, 1981-1990. https://doi.org/10.1109/TPWRD.2018.2808381

[8] Ooi, B.T. and Wang, X. (1991) Boost Type PWM HVDC Transmission System. IEEE Transactions on Power Delivery, 6, 1557-1563. https://doi.org/10.1109/61.97692

[9] Zhao, P., Chen, Q. and Sun, K.M. (2018) A Novel Protection Method for VSC-MTDC Cable Based on the Transient DC Current Using the S Transform. Electrical Power and Energy Systems, 299-308.

https://doi.org/10.1016/j.ijepes.2017.11.007

[10] Zhao, P., Chen, Q., Sun, K.M. and Xi, C.X. (2017) A Current Frequency Component-Based Fault-Location Method for Voltage-Source Converter-Based High-Voltage Direct Current (VSC-HVDC) Cables Using the S Transform. Energies, 10, 11-15. https://doi.org/10.3390/en10081115

[11] Xi, C.X., Chen, Q. and Wang, L. (2016) A Single-Terminal Traveling Wave Fault Location Method for VSC-HVDC Transmission Lines Based on S-Transform. IEEE PES Power and Energy Engineering Conference, 25-28 October, 1008-1012. 